\title{
Application of GIS: Maritime Accident Analysis in Malaysian Waters Using Kernel Density Function
}

\author{
Sarah Isnan, Nur Hazimah Nordin, Ainul Rahman, Afiqah \\ Rosly, Adenen Aziz, Zulkifly M. R., Abu Zarim, \\ Muhammad Syafiq Bin Mohd Abu
}

Statistics from the Marine Department in Malaysian Territorial waters has shown an increase in maritime accidents. The data of maritime accidents, including latitude and longitude of the locations, are analysed using Geographical Information System with Kernel Density function. This is to visualise, locate and identify the high-risk location of maritime accidents in Malaysian waters. Using the GIS analysis, the findings suggest that the data of the high-risk maritime location is at Malacca Straits. The results showed that GIS analysis is a useful tool to analyse maritime accidents data and can be used as a guidance for navigators to plan their passage in order to avoid maritime accidents.

\section{KEY WORDS}

$\sim$ Geographical Information System

$\sim$ Kernel density

$\sim$ Maritime accidents

$\sim$ Malacca straits

$\sim$ Malaysian water

$\sim$ Spatial analysis

Universiti Pertahanan Nasional Malaysia, Kuala Lumpur, Malaysia

e-mail: sarahmohdisnan@gmail.com

doi: 10.7225/toms.v10.n02.004

This work is licensed under (cc) BY

Received on: 20.05.2021 / Revised on: 20.08.2021 / Accepted on: 01.09.2021 / Published: 21.10.2021

\section{INTRODUCTION}

Maritime traffic has been used as a way to transport goods for over 3,000 years and this industry has developed rapidly to avoid maritime accidents that could cause damages to the ship and goods, pollution, and even deaths. Maritime accidents are divided into three categories: those resulting in very serious causalities, serious causalities, and less serious causalities (IMO, 2008). It is a global issue and numerous research has been done in studying their patterns, trends, and consequences.

According to the United Nations Convention on the Law of the Sea, Internal Waters are the sea areas on the landward side of the baselines, while the sea areas comprising the territorial sea, exclusive economic zone, and continental shelf lie on the seaward side of the baselines. For security and enforcement by the Malaysian Coast Guard, Malaysian waters include internal waters, territorial sea, continental shelf, and an exclusive economic zone. Malaysian water areas span over approximately $500,000 \mathrm{~km}^{2}$.

According to the Ministry of Transport (2019), more than 55,000 ships enter main ports in Malaysia annually, such as the West Port and North Port at Port Klang, Port of Tanjung Pelepas, Penang Port, and Port of Bintulu. This high-density traffic and the high number of ships entering the main ports in Malaysia have made Malaysia one of the competitors in the maritime industry. However, it also affects the safety of Malaysian waters (Asnida \& Wahab, n.d.). Hence, a study of maritime accidents is crucial to warn navigators of heavy traffic in certain areas, especially in Malacca Straits. 


\section{LITERATURE REVIEW}

Most of the scholars focused on the analysis of the maritime accidents data using GIS such as Huang et al., (2013), Acharya et al., (2017) and Zhang et al., (2020). Both Huang et al., (2013) and Acharya et al., (2017) used Buffer analysis to study distribution of maritime accidents. On the other hand, Zhang et al., (2020) used Kernel Density analysis to study distribution patterns of maritime accidents worldwide. Ugurlu et al., (2012) and Sigua \& Aguilar (2003) created a new database of ship accidents using GIS. Dobbins and Abkowitz (2010) simulated ship routes using GIS in order to analyse ship traffic in the US waters.

Based on the literature review, most of the researchers have used GIS to analyse maritime accidents, but they have only emphasised general global maritime accidents in certain areas. However, no research on GIS analysis has been done in Malaysian waters. Hence, this research is important to visualise and map out the trends of maritime accidents in Malaysian waters. This will help in future coastal planning and safety management, as well as decision making.

\section{METHODOLOGY}

\subsection{Spatial Analysis in GIS}

In GIS, spatial data that contains attributes can be visualised in a map to predict an incident by an interactive method. Different layers of maps which contain different spatial data and attributes could be combined to produce a single map. The spatial analysis is a tool in ArcGIS which is able to visualise and model the spatial data geographically. In addition, the output can be explored to predict any upcoming situation. This analysis is powerful in assessing the topographical suitability of different purposes, making predictions of output, and analyse and interpret the changes occurring based on the results produced, so that users can solve the problem efficiently (Esri, 2018).

\subsection{Kernel Density Analysis}

Geographic information system is a computer system designed to capture, query, analyse, and display geospatial data (K.T Chang, 2019). Kernel density analysis is one of the tools in GIS that is used for hot spot analysis. This method analyses location and spatial extent of incidents accurately. Statistically, Kernel density technique is a better hot spot identifier than the cluster analysis techniques (Shahrabi and Pelot, 2009). Kernel density method generalises incident occurrences over the entire study area, while hot spot techniques provide statistical summaries for the incidents (Shahrabi and Pelot, 2009). This method calculates densities in all locations, whereas other hot spot analysis defines the boundary of hot spot areas arbitrarily (Shahrabi and Pelot, 2009). Kernel density method creates a continuous surface to represent density variability over the entire study area, not just in certain cluster, as is the case with other hot spot techniques (Shahrabi and Pelot, 2009).

The estimation for new coordinates at a point $(m, n)$ is shown in Figure 1. The predicted density at a new $(x, y)$ location is determined by the following formula:

$$
\text { Density }=\frac{1}{(\text { radius })^{2}} \sum_{i=1}^{n}\left[\frac{3}{\pi} \cdot \text { pop }_{i}\left(1-\left(\left(\frac{\text { dist }_{i}}{\text { radius }^{2}}\right)^{2}\right)^{2}\right], \text { For distance } i<\right.\text { radius }
$$

where:

- $\quad i=1 \ldots \ldots$ are the input points. Only include points in the sum if they are within the radius distance of the $(x, y)$ location

- $\quad p o p_{i}$ is the population field value of point $\mathrm{i}$, which is an optional parameter

- $\quad d_{\text {ist }}$ is the distance between point $i$ and the $(x, y)$ location

Figure 1.

Formula to Estimate Density for Points Surface (Spurr and Silverman, 1988).

\subsection{Study Area}

The study area focuses on Malaysian waters. Data from the Marine Department consists of four different years of accident (2016 to 2019), types of vessels, type of accidents, longitude and latitude of location of accidents. The data is then processed in ArcMap, which shows the latitude and longitude of each accident. Subsequently, the map is analysed using GIS Kernel Density Analysis to predict the vulnerable area of maritime accidents in order to improve safety management planning. 
The raw data that was received from the Marine Department of Malaysia has undergone quality checking to ensure accurate attributes and spatial data. After that, the latitude and longitude are converted into radian format, so that the GIS will be able to map and visualise the data in an interactive map. The work process of the research is shown in Figure 2.

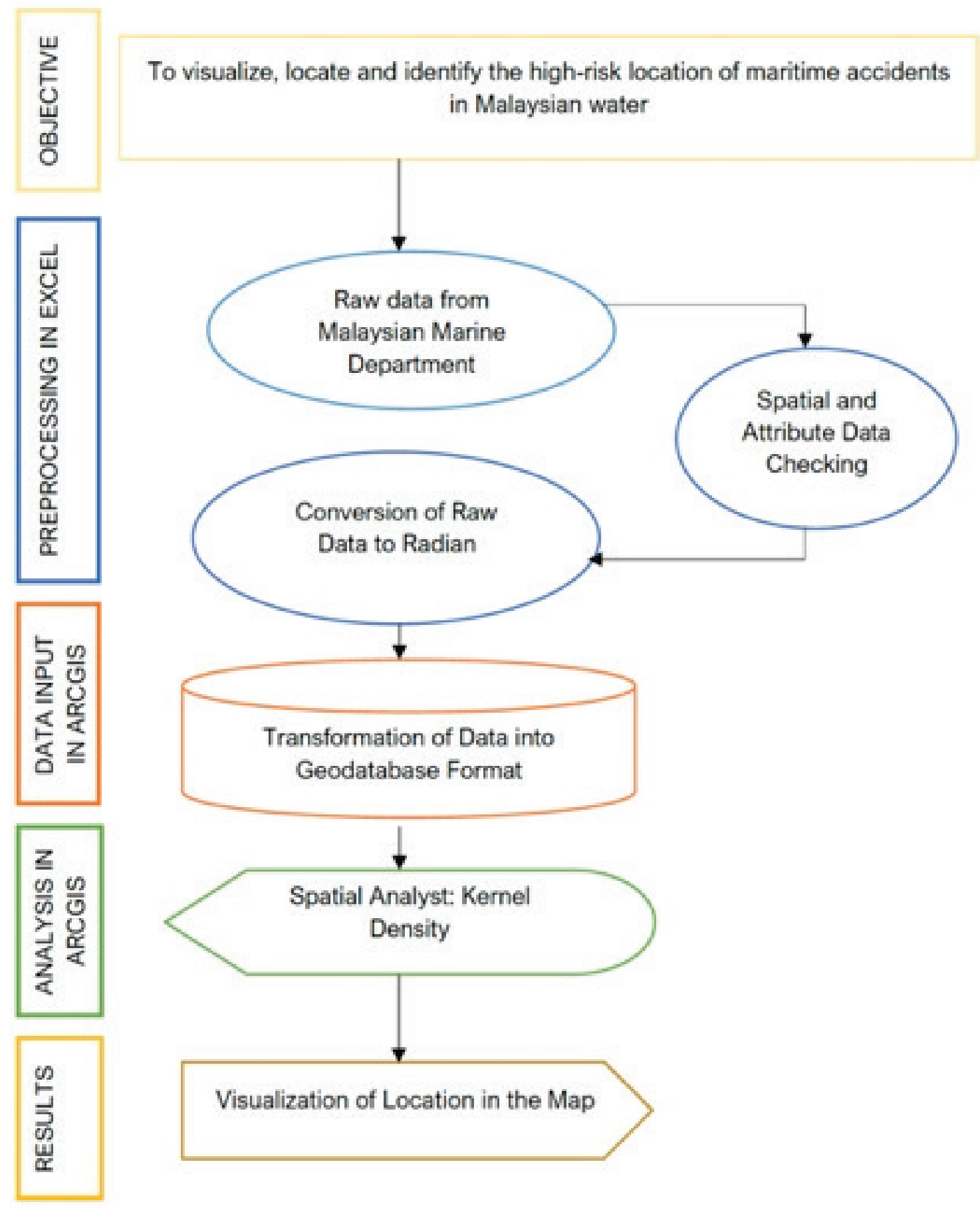

Figure 2.

Research Work Process. 


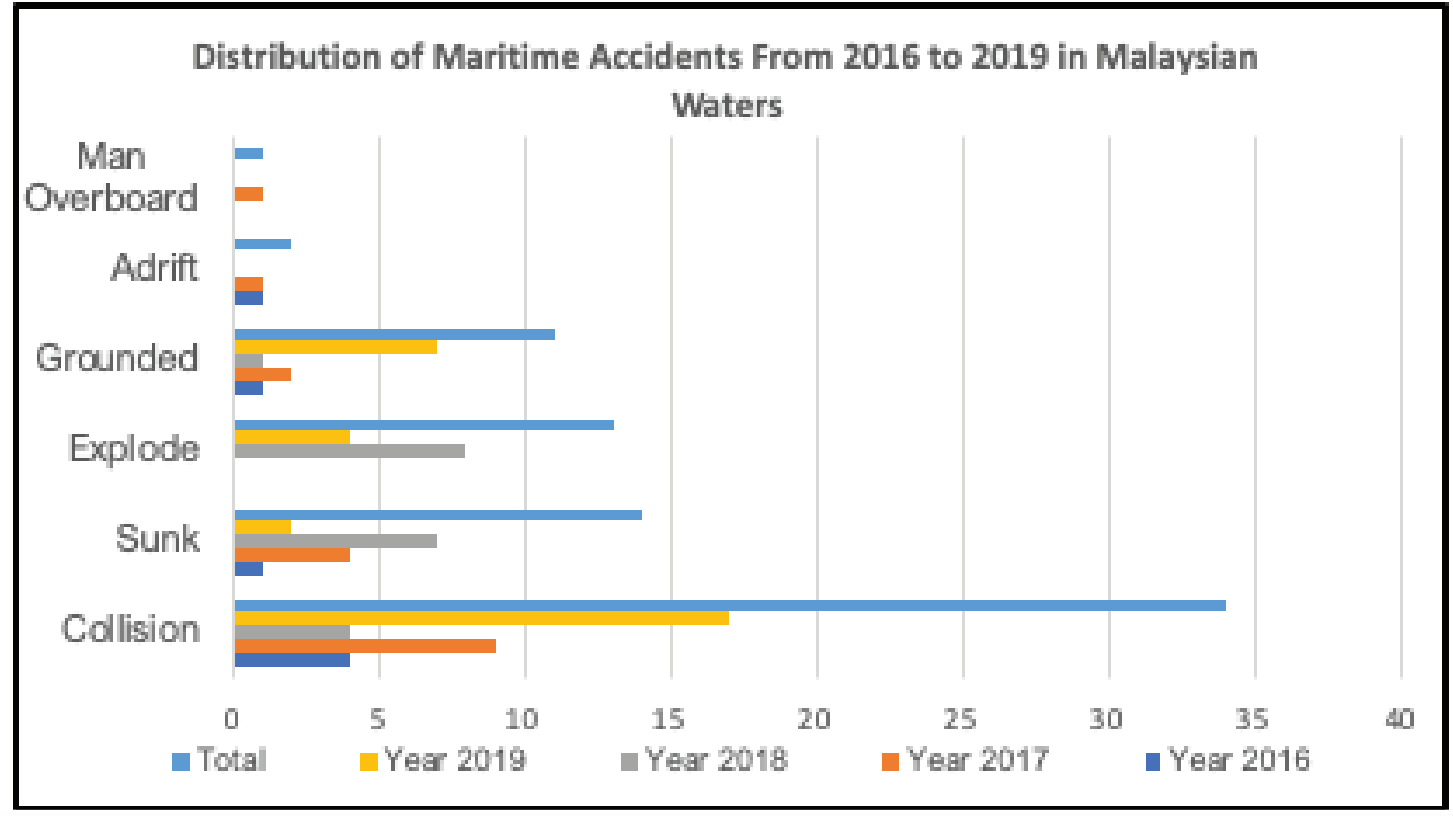

Figure 3.

Distribution of Maritime Accidents From 2016 to 2019 in Malaysian Waters.

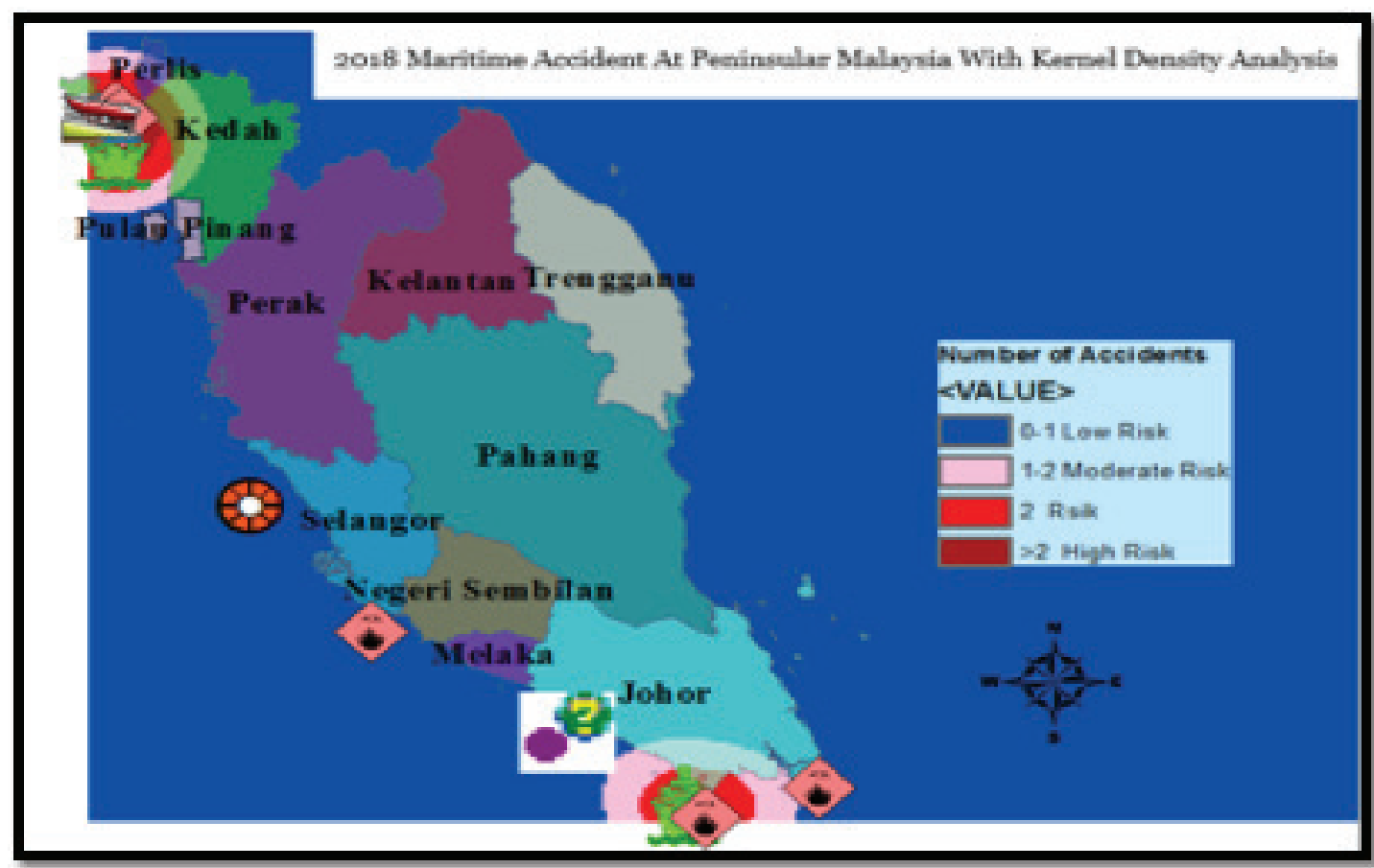

Figure 4

2018 Maritime Accident at Peninsular Malaysia with Kernel Density Analysis. 
Figure 3 shows the distribution of maritime accidents from 2016 to 2019 in Malaysian Waters. The types of maritime accidents that occurred from 2016 to 2019 in Malaysian Waters were man overboard, adrift, grounding, explosion, sunk and vessel collision. As can be seen in the graph, the highest number of accidents occurring in 2016 was vessel collision, and the lowest man overboard. The most frequent accidents occurring in 2017 were vessel collisions, while the rarest were man overboard and adrift. In 2018, the majority of accidents were related to vessel explosion, and the lowest were adrift and man overboard. The highest number of accidents occurring in 2019 was vessel collision, while the lowest was man overboard and adrift. According to Ezequiel and Marin (2014), even with advanced technologies and management, any type of maritime accident, such as collision, explosion, and sinking can happen.

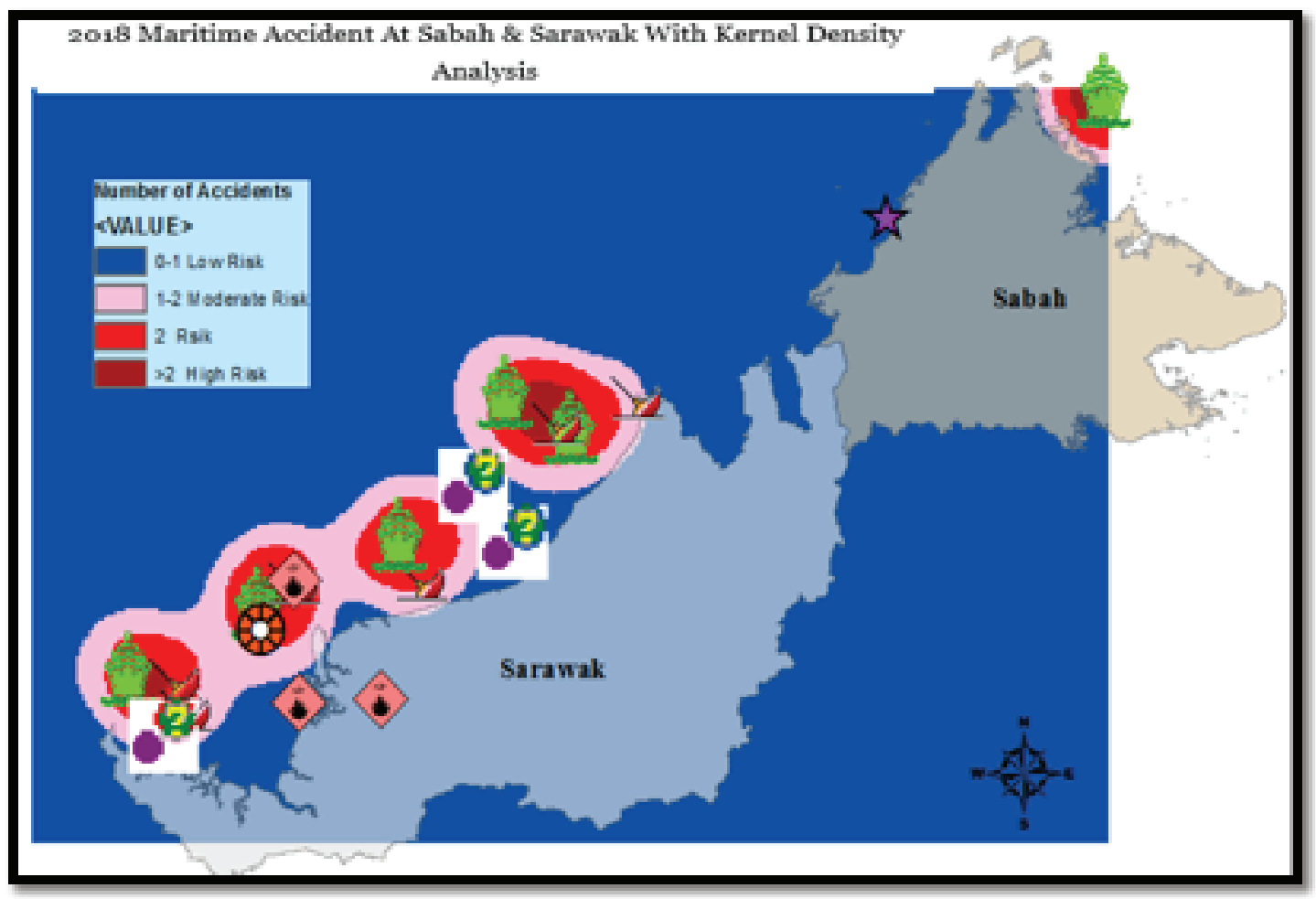

Figure 5 .

2018 Maritime accident at Sabah \& Sarawak with Kernel Density analysis.

Figures 4 and 5 show maritime accidents in Malaysia during the year 2018, after Kernel Density analysis was done. The high occurrence of accidents is reported at Singapore Straits and Sarawak territorial sea. The result of Kernel Density function analysis has produced different types of contour to indicate the highest to the lowest risk of accidents. Firstly, the dark blue label indicates the lowest or low-risk area of accidents. Next, the label that is pink in colour indicates moderate risk area of accidents. The red label indicates the areas that are categorised as risky. Finally, the high-risk area is highlighted with a darker red colour. More than 100,000 ships navigate through the Straits of Malacca annually. It has a high traffic density as it is the shortest route for vessels from the Middle East to China (Abdul Wahab, 2017).
One of the possible causes of accidents at Malacca Straits is the restricted visibility due to haze caused by forest and bush fires in Sumatra. This has affected the safe navigation through the waterways, and it remains a threat to mariners even today.

Other than that, groundings are also one of the frequent accidents along the Straits. With the shallow seafloor along the Singapore Straits being the most notorious for groundings, some ships get stuck while navigating along the stretches of the Malacca Straits (Ahmad, 2014). On top of that, ships that are not adequately maintained or are suffering mechanical problems contribute to the risk of accidents. A power or steering failure while navigating busy or challenging waters can quickly turn into a severe situation (Fadzlon, n.d.). 


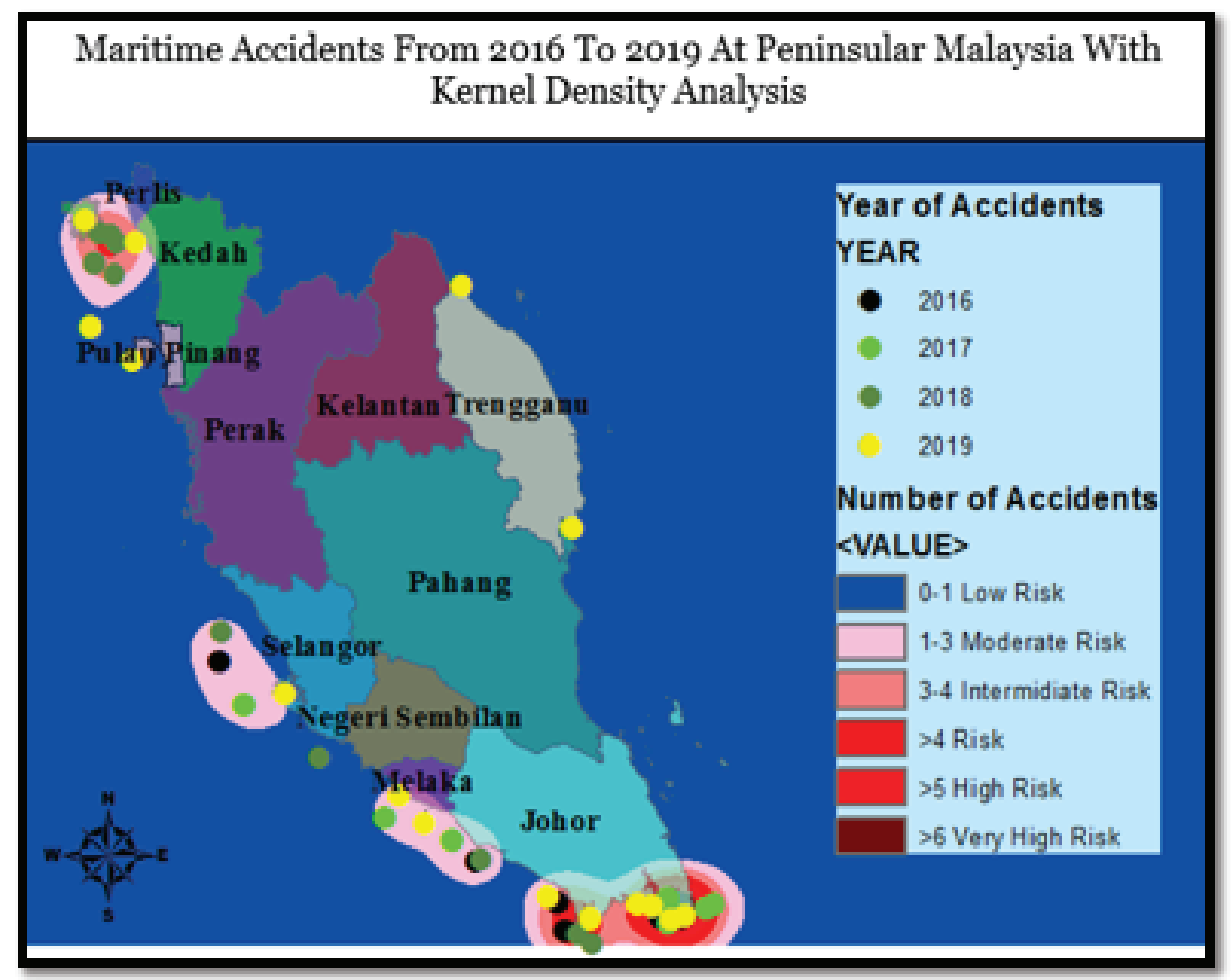

Figure 6.

Maritime Accidents from 2016 to 2019 at Peninsular Malaysia with Kernel Density analysis.

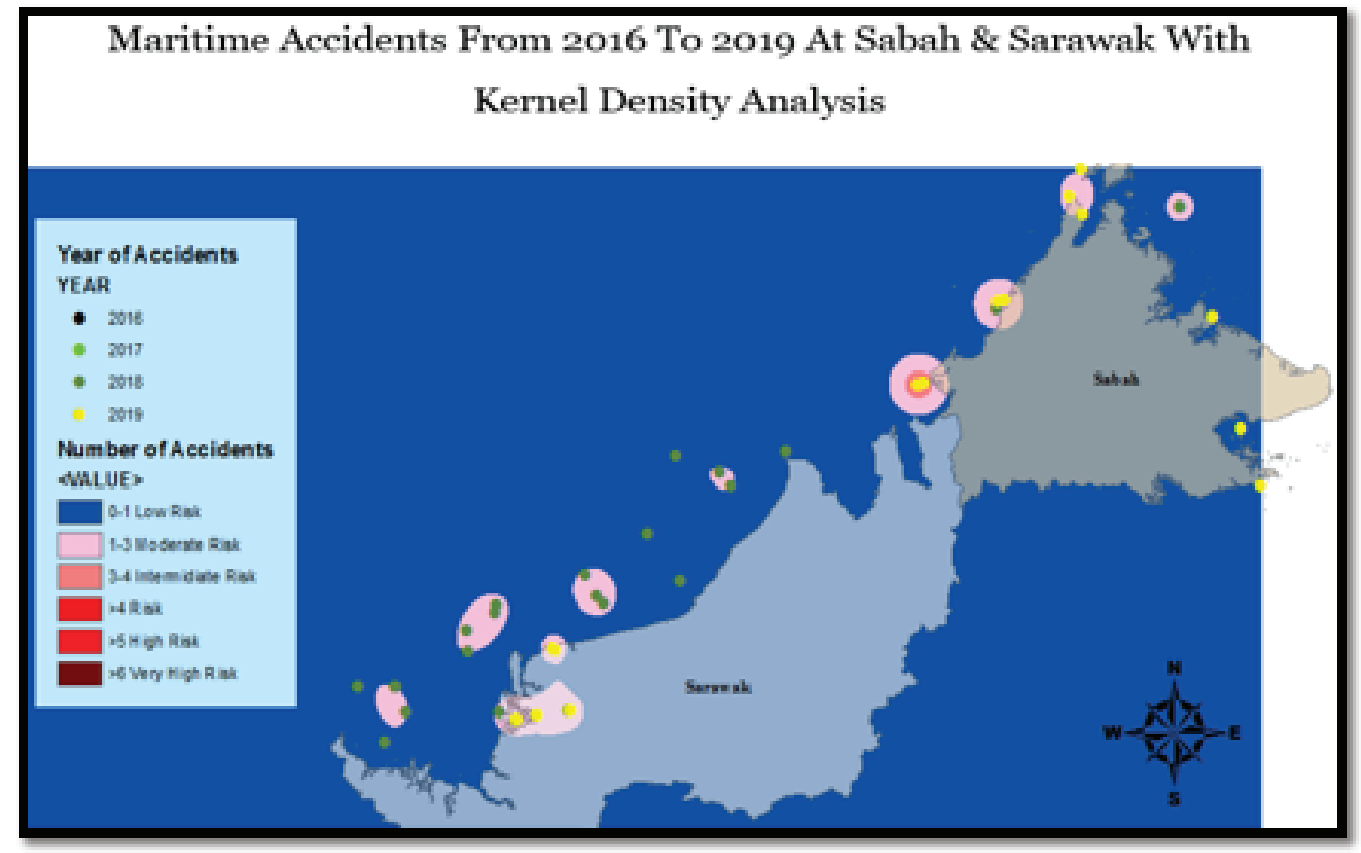

Figure 7.

Maritime accidents from 2016 to 2019 at Sabah \& Sarawak with Kernel Density analysis. 
Figure 6 and 7 show Kernel Density analysis of maritime accidents in Malaysia from the year 2016 to 2019. Relationship of types of colour to the frequency of accidents is categorised in Table 1.

Table 1.

Relationship of colour on the map with frequency of accidents.

\begin{tabular}{lll} 
Contour on the Maps & Category of Location & Frequency of Accidents \\
\hline Blue & Low risk & $<1$ \\
\hline Pink & Moderate & 2 \\
\hline Light Red & Intermediate & 3 \\
\hline Red & Risk & 4 \\
\hline Dark Red & High Risk & 5 \\
\hline Very Dark Red & Very High Risk & $>6$ \\
\hline
\end{tabular}

Based on Kernel Density Analysis, high risk and very highrisk locations are at Straits of Malacca and Singapore Straits. In addition, the Straits' most difficult conditions lie between Horsburgh Lighthouse and One Fathom Bank Lighthouse, about 217 miles away. Moderate risk is recorded for this area. The remaining 500 miles are more accessible to the sea. As masters are free to plan their course, the apparent trend is to use the shortest route. This means that many ships draw the same courses that cause them to overtake the narrow limits of the lane. Although the implementation of Traffic Separation Schemes (TSS) has considerably assisted traffic management, with different types of vessels travelling at different speeds and crews, there is still a risk of collision and grounding (Fadzlon, n.d.).

In Kedah waters, kernel density analysis detects intermediate risk and moderate risk area of maritime accidents. This is because vessels seldom cross this area. Based on the analysis, maritime accidents at Sarawak and Sabah are moderate to low. Navigators seldom cross this waterway as they usually use Malacca Straits, being the shortest route to cross from the Middle East to China (Abdul Wahab, 2017).

\section{CONCLUSION}

Kernel Density analysis function in ArcMap is able to produce an output of map with the analysis of dense maritime accidents location. Geographical Information System is able to produce output of the pointed location of maritime accidents and analysis of the highest and lowest number of the accidents. From this research, any agencies or government may be able to improve the safety on sea by surveying the location that has high a number of accidents and avoiding them. Navigators also need to be extra careful when navigating through the Straits of Malacca.
For the recommendation of future research, the researcher suggests adding details of the location of maritime accidents information on the ArcMap. Details such as water depth, navigation equipment like buoys and lighthouses, tidal stream and current, as well as location of anchorage, could be added so that the ArcMap will be more helpful to navigators in planning their passage to avoid maritime accidents.

\section{REFERENCES}

Abdul Wahab, N., 2021. Maritime Transport Safety in Malaysia. Unescap. Available at: https://www.unescap.org/sites/default/files/\%28Session\%203\%29\%20Malaysia Maritime\%20transport\%20safety.pdf, accessed on: 1 March 2021.

Acharya, T.D., Yoo, K.W. \& Lee, D.H., 2017. GIS-based Spatio-temporal Analysis of Marine Accidents Database in the Coastal Zone of Korea. Journal of Coastal Research, 79, pp.114-118. Available at: http://dx.doi.org/10.2112/si79-024.1

Dobbins, J.P. \& Abkowitz, M., 2010. Use of Advanced Information Technologies for Marine Accident Data Analysis Visualization and Quality Control. Journal of Transportation Safety \& Security, 2(1), pp.1-13. Available at: http://dx.doi.org/10.1080/19439960903560312.

Ezequiel, J. and Marin, M., 2014. Induced Maritime Accidents, July 2014

Huang, D.-Z., Hu, H. \& Li, Y.-Z., 2013. Spatial Analysis of Maritime Accidents Using the Geographic Information System. Transportation Research Record: Journal of the Transportation Research Board, 2326(1), pp.39-44. Available at: http://dx.doi.org/10.3141/2326-06.

Sigua, R. and Aguilar, G., 2003. Maritime incident analysis using GIS, Journal of the Eastern Asia Society for Transportation Studies, 5(11), pp. 778-793.

Ugurlu, O., Yildirim, U. and Yuksekyildiz, E., 2012. Marine accident analysis with GIS, NAV International Conference on Ship and Shipping Research.

Zhang, Y. et al., 2021. Spatial patterns and characteristics of global maritime accidents. Reliability Engineering \& System Safety, 206, p.107310. Available at: http://dx.doi.org/10.1016/j.ress.2020.107310. 